ЧРЕСФИСТУЛЬНАЯ НАНОЭЛЕКТРОИМПУЛЬСНАЯ ЛИТОТРИПСИЯ В ЛЕЧЕНИИ ХОЛЕДОХОЛИТИАЗА

Бабак А.И. ${ }^{1}$, Можаева Е.А. ${ }^{1}$, Расковалов Д.А. ${ }^{1}$, Андриенко И.С. ${ }^{1}$, Прудков М.И. ${ }^{2}$

1 ГБУЗ СО «Свердловская областная клиническая больница №1» 620102 ул. Волгоградская 185, г. Екатеринбург, Россия

2 ФГБОУ ВО «Уральский государственный медицинский университет» МЗ РФ, 620028 ул. Репина 3, г. Екатеринбург, Россия

\title{
Резюме.
}

В 2003 году российскими разработчиками был предложен новый способ разрушения конкрементов электрическими импульсами наносекундной продолжительности, сходный по механизму дробления $\mathrm{c}$ контактной электрогидравлической литотрипсией, но обладающий рядом преимуществ. Цель работы: оценить возможности чресфистульной наноэлектроимпульсной литотрипсии (НЭИЛ) в лечении холедохолитиаза. Мы использовали наноэлектроимпульсный литотриптор «Уролит» производства фирмы «Медлайн» (Томск). 66 пациентам с крупными и/или неподвижными конкрементами и дренажами желчных протоков была выполнена чресфистульная НЭИЛ. Она оказалась успешной у 63 пациентов (95.5\%). Применение НЭИЛ позволило сохранить сфинктерный аппарат большого сосочка двенадцатиперстной кишки в 89\% случаев. Чресфистульная НЭИЛ - новый высокоэффективный и безопасный метод дробления желчных камней.

Ключевые слова: холедохолитиаз, чресфистульная фиброхоледохоскопия, литэкстракция, контактная литотрипсия, наноэлектроимпульсная литотрипсия.

\section{TRANSFISTULAR NANOELECTROIMPULSE LITHOTRIPSY IN THE TREATMENT OF CHOLEDOCHOLITHIASIS}

Babak A.I. ${ }^{1}$, Mozhaeva E.A. ${ }^{1}$, Raskovalov D. A. ${ }^{1}$, Andrienko I. S. ${ }^{1}$, Prudkov M.I. ${ }^{2}$

${ }^{1}$ SBIH SR «Sverdlovsk Regional Clinical Hospital No 1» 620102 Volgogradskaya st. 185, Ekaterinburg, Russia

2 FSBI HPE «Urals State Medical University» MOH Russia, 620028 Repina st. 3, Ekaterinburg, Russia

\section{Summary.}

In 2003, Russian developers proposed a new method of crushing stones by electric impulses of nanosecond duration, which has several advantages over contact electrohydraulic lithotripsy. The aim of the study was to evaluate the possibilities of transfistular nanoelectroimpulse lithotripsy (NEIL) in the treatment of choledocholithiasis. A nanoelectroimpulse lithotriptor "Urolit", manufactured by Medline Ltd. (Tomsk, Russia), was used to break down the gallstones. 66 patients with large and/or unmovable bile duct stones and bile ducts drains were performed transfistular NEIL. It was successful in 63 patients $(95.5 \%)$. NEIL 
made it possible to perform removal of large and/or unmovable gallstones without destroying the sphincters of the major duodenal papilla in $89 \%$ cases. Transfistular NEIL is a new highly effective and safe method of crushing gallstones.

Keywords: choledocholithiasis, gallstones, transfistular choledochoscopy, lithotripsy, nanoelectroimpulse lithotripsy.

\section{Введение.}

При чресфистульном лечении холедохолитиаза наибольшие трудности возникают при попытках извлечь крупные и/или неподвижные камни $[1,2,3]$.

В 2003 году российскими разработчиками был предложен новый способ разрушения конкрементов электрическими импульсами наносекундной продолжительности, сходный по механизму дробления с контактной электрогидравлической литотрипсией (ЭГЛ), но обладающий рядом преимуществ. Как при ЭГЛ, так и при наноэлектроимпульсной литотрипсии (НЭИЛ) используется гибкий зонд, содержащий 2 изолированных коаксиально расположенных электрода. При контакте головки зонда с конкрементом на электроды подается электрический импульс. При высоковольтных импульсах длительностью $10^{2}-10^{3}$ наносекунд твердый диэлектрик (конкремент) имеет более низкое сопротивление пробоя, чем жидкая среда. Поэтому при НЭИЛ, в отличие от ЭГЛ, электрический пробой, создающий ударную волну, происходит не в жидкой среде, а в толще конкремента. Разрушение конкрементов при использовании НЭИЛ происходит при меньших значениях суммарной энергии и меньшем количестве импульсов, чем при ЭГЛ. Усредненная удельная объемная энергия при НЭИЛ составляет 0,8 Дж/мм ${ }^{3}$ а при ЭГЛ - 2,6 Дж/ $\mathrm{MM}^{3} \cdot[4]$

НЭИЛ нашла применение в урологии для разрушения мочевых камней. [5, 6] Сведения об использовании НЭИЛ в лечении холедохолитиаза в доступных нам источниках отсутствуют.

Цель работы: оценить возможности чресфистульной НЭИЛ в лечении холедохолитиаза.

Материалы и методы исследования. В исследовании представлены 66 пациентов с крупными и/или трудноизвлекаемыми конкрементами в желчных протоках, которые проходили лечение в хирургической клинике СОКБ №1 г. Екатеринбурга с 2013 по 2016 годы. Всем пациентам ранее были выполнены холецистэктомия и дренирование желчных протоков в лечебных учреждениях Свердловской области (население 4,3 млн.). [7]

63 пациента имели дренажи Кера или Холстеда-Пиковского, 3 пациента - чрескожные чреспеченочные дренажи. Возраст пациентов составлял от 30 до 89 лет. 46 пациентов женщины, 20 - мужчины. 
Эндобилиарное лечение этих пациентов включало следующие этапы: подготовка свища, чресфистульная НЭИЛ и механическая литэкстракция под контролем фиброхоледохоскопии (ФХС), при необходимости - эндоскопическая папиллосфинктеротомия (ЭПСТ) по вынужденным или клиническим показаниям. [1]

При диаметре сформировавшегося свища 6 мм и более подготовка заключалась в извлечении дренажной трубки под контролем рентгеноскопии. При свищах меньшего диаметра мы осуществляли дилатацию подпеченочных свищей путем поэтапной смены дренажных трубок нарастающего диаметра с шагом 2-4 Fr и интервалом в 2-3 дня. Замену трубок производили по проводнику под контролем рентгеноскопии. Каждую последующую трубку устанавливали в свищ плотно, но без усилия. [1] Чреспеченочные свищи поэтапно дилатировали полыми бужами.

Для проведения чресфистульной ФХС мы использовали фиброскоп СНF Т20 фирмы «Olympus», с внешним диаметром 6 мм и инструментальным каналом 2,6 мм и эндоскопические инструменты производства фирм «Endo-Flex» и «Boston Scientific».

Подвижные конкременты и их обломки после литотрипсии диаметром менее 6 мм извлекали при помощи металлических корзинок. Неизвлекаемые крупные и/или неподвижные камни подвергали НЭИЛ. Мы использовали наноэлектроимпульсный литотриптор «Уролит» с зондами диаметром 1,2 мм, производства фирмы «Медлайн» (Томск). Зонд для НЭИЛ проводили через инструментальный канал холедохоскопа, дробление осуществляли под визуальным контролем. Мощность составляла 0,6-1 Дж. Дробление начинали с 0,6 Дж, повышая мощность при недостаточном эффекте с шагом 0,1 Дж. Количество импульсов на 1 операцию колебалось от 5 до 25. Применяли только режим единичных импульсов.

Если не удавалось раздробить и/или извлечь конкременты только чресфистульным доступом мы выполняли эндоскопическую папиллосфинктеротомию (ЭПСТ).

При неэффективности эндобилиарной санации или утере свища пациентам выполняли полостную операцию с повторным дренированием желчных протоков.

\section{Результаты и обсуждение.}

Размер конкрементов составил от 5 до 28 мм. Количество конкрементов: 1 камень 49 случаев, 2 камня - 8 случаев, 3 камня - 3 случая, 4 и более конкрементов - 6 случаев. 48 пациентам дробление проведено в 1 этап, 14 - в 2 этапа и 4 - в 3 этапа и более.

В 4 случаях после литотрипсии произошла миграция и вклинение обломков конкрементов в ампуле большого сосочка двенадцатиперстной кишки (БСДК). Этим пациентам была выполнена ЭПСТ с низведением камней в кишку. 
Еще в 2 случаях ЭПСТ потребовалась, чтобы переместить конкремент терминального отдела холедоха проксимально для сопоставления с зондом литотриптора.

3 ЭПСТ выполнены по поводу папиллостеноза. Осложнений ЭПСТ не отмечено.

Неудачи. В 2 случаях не удалось сопоставить зонд литотриптора с конкрементом, расположенным во внутрипеченочных протоках. В одном случае произошла утеря свища, этому пациенту сделана ЭПСТ для восстановления оттока желчи. Всем 3 пациентам выполнены полостные операции.

У 63 пациентов $(95,5 \%)$ литотрипсия оказалась успешной. Техническая эффективность литотрипсии (в тех случаях, когда удалось сопоставить зонд литотриптора с конкрементом) составила 100\%. Сохранён сфинктерный аппарат БСДК у 56 из 63 пациентов, не имевших клинических показаний к ЭПСТ - это 89\%.

Заключение. Чресфистульная НЭИЛ под контролем ФХС - новый высокоэффективный и безопасный метод дробления желчных камней.

\section{Список литературы:}

1. Козлов В.А., Прудков М.И. Чресфистульные вмешательства на желчных путях. Свердловск: Издательство Уральского университета, 1987.

2. Прудков М.И., Ковалевский А.Д., Натрошвили И.Г. Эндоскопические чресфистульные и трансабдоминальные вмешательства при холангиолитиазе // Анналы хирургической гепатологии. 2013. № 18(1). С. 42-53.

3. Shim C.-Sh. 39 Biliary Lithotripsy // Classen M., Tytgat G.N.J., Lightdale C.J., eds. Gastroenterological Endoscopy. Stuttgart: Thieme. 2010. C. 443-456. doi:10.1055/b-0034-84087 4. Мартов А.Г., Гудков А. В., Диамант В. М., Чеповецкий Г.И., Лернер М.И. Сравнительное исследование эффективности электроимпульсного и электрогидравлического литотрипторов in-vitro // Экспериментальная и клиническая урология. 2013. № 4. С. 90-96. 5. Румянцев А.А., Дутов В.В., Беляев В.В., Саакян А.А., Беляев Д.В., Попов Д.М. Трансуретральная контактная электроимпульсная уретеропиелолитотрипсия // Урология. 2011. № 3. C. 40-43.

6. Гудков А.В., Бощенко В.С., Афонин В.Я., Лозовский М.С. Зависимость эффективности и безопасности ретроградной контактной электроимпульсной уретеролиторипсии от расположения и размеров конкремента // Экспериментальная и клиническая урология. 2013. № 4. С. 100-106.

7. Прудков М.И., Малинкин А.В., Столин А.В., Чернядьев С.А. и др. Неотложная хирургия. Клинические рекомендации по оказанию медицинской помощи населению Свердловской области. Екатеринбург, 2013. 


\section{Информация об авторах}

Бабак Андрей Иванович, ГБУЗ СО «Свердловская областная клиническая больница №1», заведующий отделением - врач-эндоскопист, +79502018598, andrewbabak@ mail.ru

Можаева Елена Анатольевна, ГБУЗ СО «Свердловская областная клиническая больница №1», врач-эндоскопист, +79193829951, mozhaeva.72@ mail.ru

Расковалов Дмитрий Александрович, ГБУЗ СО «Свердловская областная клиническая больница №1» врач-эндоскопист, +79122800445, d.raskovalov@ bk.ru

Андриенко Ирина Сергеевна, ГБУЗ СО «Свердловская областная клиническая больница №1», врач-эндоскопист, +79193806796, iis82@mail.ru

Прудков Михаил Иосифович, ФГБОУ ВО «Уральский государственный медицинский университет» МЗ РФ, заведующий кафедрой общей хирургии и хирургических болезней, доктор медицинских наук, профессор, +73433511642, miprudkov@ gmail.com 